\title{
Technical note: Greenhouse gas flux studies: an automated online system for gas emission measurements in aquatic environments
}

\author{
Nguyen Thanh Duc ${ }^{1,4}$, Samuel Silverstein ${ }^{2}$, Martin Wik ${ }^{3}$, Patrick Crill ${ }^{3}$, David Bastviken ${ }^{4}$, and Ruth K. Varner ${ }^{1}$ \\ ${ }^{1}$ Institute for the Study of Earth, Oceans and Space and Department of Earth Sciences, \\ University of New Hampshire, Durham, 03824, New Hampshire, USA \\ ${ }^{2}$ Department of Physics, Stockholm University, 106 91, Stockholm, Sweden \\ ${ }^{3}$ Department of Geological Sciences, Stockholm University, 106 91, Stockholm, Sweden \\ ${ }^{4}$ Department of Thematic Studies - Environmental Change, Linköping University, 581 83, Linköping, Sweden
}

Correspondence: Nguyen Thanh Duc (thanh.duc.nguyen@liu.se)

Received: 18 February 2019 - Discussion started: 4 April 2019

Revised: 9 September 2019 - Accepted: 1 April 2020 - Published: 6 July 2020

\begin{abstract}
Aquatic ecosystems are major sources of greenhouse gases (GHGs). Robust measurements of natural GHG emissions are vital for evaluating regional to global carbon budgets and for assessing climate feedbacks of natural emissions to improve climate models. Diffusive and ebullitive (bubble) transport are two major pathways of gas release from surface waters. To capture the high temporal variability of these fluxes in a well-defined footprint, we designed and built an inexpensive device that includes an easily mobile diffusive flux chamber and a bubble counter all in one. In addition to automatically collecting gas samples for subsequent various analyses in the laboratory, this device also utilized a low-cost carbon dioxide $\left(\mathrm{CO}_{2}\right)$ sensor (SenseAir, Sweden) and methane $\left(\mathrm{CH}_{4}\right)$ sensor (Figaro, Japan) to measure GHG fluxes. Each of the devices was equipped with an XBee module to enable local radio communication (DigiMesh network) for time synchronization and data readout at a server controller station on the lakeshore. The software of this server controller was operated on a lowcost computer (Raspberry Pi), which has a $3 \mathrm{G}$ connection for remote control and monitor functions from anywhere in the world. This study shows the potential of a low-cost automatic sensor network system for studying GHG fluxes on lakes in remote locations.
\end{abstract}

\section{Introduction}

Despite the fact that lakes and impoundments only cover around $3.7 \%$ of the Earth's land mass (Downing et al., 2006; Verpoorter et al., 2014), their contribution to global carbon dioxide $\left(\mathrm{CO}_{2}\right)$ and greenhouse gas (GHG) budgets is substantial (Tranvik et al., 2009; Bastviken et al., 2011). Lake emissions are not only large, but previous studies also highlight large uncertainties in overall emission estimates. For example, a recent synthesis of $\mathrm{CH}_{4}$ emissions from northern lakes and ponds reveals that these aquatic environments contribute $16.5 \mathrm{TgCH}_{4} \mathrm{yr}^{-1}$, equivalent to more than $65 \%$ of the inverse model calculation of all natural $\mathrm{CH}_{4}$ sources in high-latitude regions where $\mathrm{CH}_{4}$ fluxes were believed to be largely emitted from wetlands (Wik et al., 2016b). In addition, the climate sensitivity of natural emissions of GHGs is not well understood, but metadata analyses showed that $\mathrm{CH}_{4}$ emissions and the ratio of $\mathrm{CH}_{4}$ emissions to $\mathrm{CO}_{2}$ emissions increase markedly with increasing temperature (YvonDurocher et al., 2014; Marotta et al., 2014). Previous field studies of GHG emissions are still limited in their spatial and temporal resolution, which potentially results in poorly resolved measurements and biased estimates (Wik et al., 2016a). For this reason, there is a need for new and improved approaches to studying the emission of $\mathrm{CH}_{4}$ and $\mathrm{CO}_{2}$ from open freshwater ecosystems at both higher temporal and spatial resolutions.

Using conventional techniques with well-defined footprints, emitted gases can be trapped in air-filled flux cham- 
bers (FC) or submerged water-filled funnels (Chanton and Whiting, 1995). When properly designed with a lightweight chamber that has limited intrusion into the water surface, a mooring to enable the chamber to follow wave and water motion, the flux chamber method, which can trap both diffusive and ebullitive (bubble) fluxes, has been repeatedly shown to have negligible bias in gas flux measurement at the air-water interface relative to $\mathrm{SF}_{6}$ assessments (Cole et al., 2010) or other independent, non-invasive methods (Gålfalk et al., 2013; Lorke et al., 2015). A submerged funnel moored to allow movement around a specified area can be deployed to specifically trap gas bubbles released from the sediment surface (Wik et al., 2013). For both flux chambers and submerged funnels, the trapped gas is commonly collected manually with syringes after a specific time interval and analyzed in the laboratory. Both methods are inexpensive in terms of equipment and work well to quantify gas emission in a relatively small defined area. However, they are labor intensive due to the need for repeated visits for both deployment and sample collection and therefore often result in low temporal resolution of emission measurements. During short-term measurements, there is also a high probability of missing potentially rare and episodic ebullition events entirely. In contrast, during long-term chamber or funnel deployments, $\mathrm{CH}_{4}$ dissolution or oxidation in the water that is in contact with the trapped gas could result in an underestimation of flux. Most previous measurements reported in the literature were based on infrequent measurements within short time frames ( 0.5 to $24 \mathrm{~h})$ and likely did not capture ebullition in a representative way, thereby resulting in underestimation (Wik et al., 2016a). As a result, there is a high uncertainty in extrapolations and modeling of $\mathrm{CH}_{4}$ and $\mathrm{CO}_{2}$ emissions over time from open water ecosystems (Smith, 1985; Walter et al., 2001; Bastviken et al., 2004; Meng et al., 2012). A high frequency of measurements over long periods with broad spatial coverage of studied areas could reduce this uncertainty and result in more representative gas emission estimates. Regarding the floating chamber approach, there are automated methods in which the trapped gases in the chamber can be sampled with a system of pipes and large pumps connected to a gas analyzer (Goodrich et al., 2011; Goulden and Crill, 1997). This can better address the temporal variability, but the gas analyzer equipment is typically expensive. The chambers also need to be relatively close to the gas analyzer so this method can be limited in spatial coverage.

Carbon dioxide flux measurements require a short time period for chamber deployment due to rapid equilibration. There are commercial high-precision $\mathrm{CO}_{2}$ sensors available (e.g., Li-Cor, Vaisala- $\mathrm{CO}_{2}$ ) (Johnson et al., 2010; Anderson et al., 1999) which can be connected to chambers for $\mathrm{CO}_{2}$ analysis. However, their cost makes it difficult to afford many simultaneous measurements across a study area. Recently, Bastviken et al. (2015) proposed the use of a low-cost $\mathrm{CO}_{2}$ sensor and developed applications for $p \mathrm{CO}_{2}$ and $\mathrm{CO}_{2}$ flux measurement in outdoor environments.
High-frequency measurements of the timing of ebullitive events have been made using techniques based on video, photo and hydroacoustic methods (Ostrovsky et al., 2008; Tassin and Nikitopoulos, 1995). Acoustic methods have high potential for solving the spatial heterogeneity of gas emission, but this technique can have a high cost for equipment and there remains some uncertainty in quantifying gas emissions (Ostrovsky et al., 2008; DelSontro et al., 2015). In addition, these techniques may work well in ecosystems with frequent ebullition, but sonar scanning can be timeand power-consuming over extended periods in ecosystems where ebullition is less frequent. In such systems, there is a need for inexpensive and power-efficient equipment for continuous long-term monitoring of ebullition. Varadharajan et al. (2010) developed a low-cost automated trap to measure ebullition flux using an inverted funnel connected to a pressure sensor whose signal was recorded by a commercial data logger. This type of commercial data logger and funnel still requires manual maintenance and gas release, which also means high potential for missing ebullition events when the trap is full of gas. The eddy covariance (EC) technique is increasingly used for long-term monitoring of terrestrial and lake-dominated landscapes, but it is expensive in terms of equipment (Vesala et al., 2012; Deemer et al., 2016). In addition, EC measurements were not designed to account for any small-scale spatial variability from different types of areas that lies within the footprint of the measurement.

To increase the quality and quantity of observations of aquatic GHG emissions, we developed a low-cost, simple, robust, and portable device with a well-defined footprint for investigating gas flux at the water-air interface. This is a follow-up from our previous open-tech-published work focused on measuring $\mathrm{CH}_{4}$ using an automated flux chamber (AFC) (Duc et al., 2013), now substantially improved by including sensors to reduce the need of laborious manual sampling and analyses as well as a wireless online readout control device that has the capability to simultaneously measure ebullitive fluxes with an automatic bubble counter (ABC) and diffusive $\mathrm{CH}_{4}$ and $\mathrm{CO}_{2}$ fluxes with an automated floating chamber. Taking advantage of small, low-cost $\mathrm{CH}_{4}$ and $\mathrm{CO}_{2}$ sensors, we have modified our AFC, which is composed of a flux chamber connected to an automated control box (Duc et al., 2012), to measure $\mathrm{CH}_{4}$ and $\mathrm{CO}_{2}$ flux from aquatic environments. The $\mathrm{CH}_{4}$ sensors tested here were Taguchitype semiconductor gas sensors sold by Figaro Engineering Inc., Osaka, Japan, or Panthera Neodym Technologies, Canada (sensors described below). Eugster and Kling (2012) showed successfully that a similar sensor (TSGS2600) has potential to measure $\mathrm{CH}_{4}$ at ambient air concentrations. The sensors have a high sensitivity to relative humidity and temperature, but these responses can be corrected for to yield corrected $\mathrm{CH}_{4}$ signals (see below). The $\mathrm{CO}_{2}$ sensor used here $\left(\mathrm{CO}_{2}\right.$ Engine ELG K33 from SenseAir, Sweden) is a lowpower module that measures $\mathrm{CO}_{2}$, temperature, and relative humidity. Therefore, this $\mathrm{CO}_{2}$ sensor can provide tempera- 


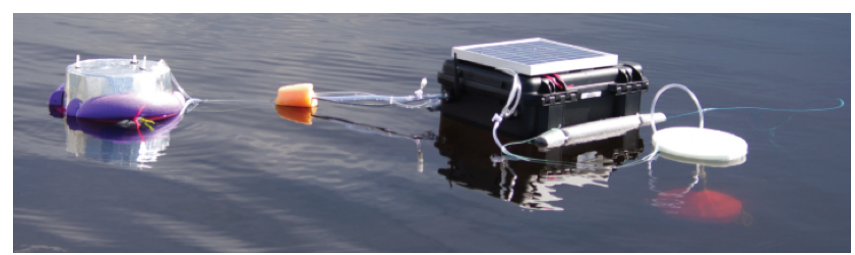

Figure 1. The photo of a deployed AFC-ABC device shows a floating control box that houses the electronics, a floating chamber, and a submerged funnel.

ture and humidity data to correct the $\mathrm{CH}_{4}$ sensor response. The sensor-equipped AFCs were combined with submerged funnels for automated detection of bubbles (the ABC). Here, we suggest a solution to automatically collect or release the trapped gas and restart the bubble trap by using a pump and valve system, which is controlled by an inexpensive microcontroller-based data logger based on the feedback of the pressure signal.

\section{Methods}

In this section, we describe the technical details of our new device (a combined $\mathrm{AFC}$ and $\mathrm{ABC}$ ) that simultaneously measures $\mathrm{CH}_{4}$ ebullition and diffusive $\mathrm{CH}_{4}$ and $\mathrm{CO}_{2}$ emissions. This device operates and communicates (to receive working parameters and send data) within a DigiMesh network using an XBee transmitter module (XBP24-AUI001J, Digi International, USA). The system consists of a floating control box that houses the electronics, a floating chamber, and a submerged funnel (Fig. 1). The control box is a watertight case which stores a power source (either a $12 \mathrm{~V} 7 \mathrm{Ah}$ lead-acid battery or a $12 \mathrm{~V} 55 \mathrm{Ah}$ lithium-ion battery; Power Pack LS 55, vuphongsolar.com, Vietnam), diaphragm pumps, electronic valves, a pressure sensor, and the electronic controller boards inside and had a solar panel mounted on the top. The control box connects to either the chamber or the funnel or both. Compared with the previous version in Duc et al. (2013), the electronic controller boards, including the power control board and the data logger board, have been redesigned to include an open $5 \mathrm{~V}$ dc supply for a $\mathrm{CH}_{4}$ sensor, an open $\mathrm{I} 2 \mathrm{C}$ connection for a $\mathrm{CO}_{2}$ sensor, and an open UART2 connection for XBee radio communication.

\subsection{Ebullition counter}

The $\mathrm{ABC}$ was based on an inverted funnel design similar to that of Wik et al. (2013), adopting the measurement principle of Varadharajan et al. (2010). From the funnel stem, a $30 \mathrm{~cm}$ PVC pipe $(10 \mathrm{~mm}$ i.d.) was attached to accumulate bubbles. The maximum trapped-bubble volume for this system is $\sim 28 \mathrm{~mL}$. The other end of the PVC pipe was attached to an inverted $10 \mathrm{~mL}$ syringe whose tip was connected to a differential pressure sensor (26PCAFA6D, Hon- eywell, Sensing and Control, Canada; this sensor was chosen for being similar to that of Varadharajan et al., 2010, and being compatible with the electronics in our system) via a polyurethane tube $(3.175 \mathrm{~mm}$ inner diameter; Clippard URT1-0805; Fig. 1). The pressure sensor was powered by regulated $10 \mathrm{Vdc}$, and its signal was amplified 495 -fold by an AD620 chip (Analog Devices, USA). Gas accumulating in the pipe pushes down the water level relative to the water level outside the pipe, and this water level difference generates a pressure that is proportional to the gas volume in the pipe. The ebullition rate $\left(\mathrm{mL} \mathrm{min}^{-1}\right)$ is determined from the change in the differential pressure inside the pipe over time; therefore, it is important to make the trap gastight.

The $\mathrm{ABC}$ can be programmed to simulate the deployment cycle of a manual trap including capturing bubbles and releasing gases when the trap is full. To enable autonomous operation for long deployment periods, not only the pressure sensor but also a pump and a two-way valve were connected to the bubble trap via the polyurethane tube and two T connectors (Fig. S1 in the Supplement). The pump and valve were powered by $12 \mathrm{~V}$ dc.

The microcontroller-based data logger board continuously reads the amplified pressure sensor signal, and a stepwise pressure increase from gas accumulation indicates an ebullition event that is recorded with date and time stamps. The bubble measuring cycle of the $\mathrm{ABC}$ in the field includes initiation, measurement, and ventilation stages. In the initiation state, the pump injects a small amount of air (about $5 \mathrm{~mL}$ ) into the sampler to push any condensation water droplets out of the tube and to have a starting pressure equivalent to the sensor detection limit. During the measurement state, bubbles are trapped in the funnel, and the pressure signal is continuously monitored by the data logger. When the pressure signal increases to a threshold level indicating that the bubbles have filled up the PVC pipe, the headspace of trapped bubbles can be either vented away or measured in a connected $\mathrm{CH}_{4}$ and $\mathrm{CO}_{2}$ sensor box. The controller activates a ventilation cycle in which the pump purges the trap, and then the valve opens for ventilation. The valve closes again when the pressure signal drops down to the initial detection limit level. This also prevents water from entering the tube, which could cause moisture blockage interfering with sensor response. The ventilation stage cycles three times until the headspace is replaced by air. This measuring cycle (Fig. S1) makes the ABC fully automated and operational over long periods - week to months or perhaps years, given adequate power supply.

The pressure data can be recorded either to an SD card on the data logger or by wireless transfer to an onshore computer for subsequent transfer to a cloud server (see Sect. 3.3 Wireless network in the Supplement). The data file is then processed (e.g, MATLAB) to extract the ebullition events from baseline noise based on the stepwise increase in the pressure signal. When the $\mathrm{ABC}$ was deployed in the field, the baseline noise increased. Even if the pressure sensor is precalibrated 
and has a temperature-compensated range from 0 to $50^{\circ} \mathrm{C}$, the weather conditions - including temperature, wind, and waves - will physically affect (shrink or expand) the bubble in the trap. Therefore, noise removal is a critical procedure in data processing to extract the bubble events.

The regular electric noise, drift, wind, and wave effects on the pressure sensor generate high-frequency, low-level signals. A bubble, on the other hand, will generate an abrupt jump that raises the level of pressure signal (Fig. 1). In general, this leads to periods with constant average pressure separated by a finite number of abrupt signal jumps to new pressure levels due to bubbling. This reflects a piecewise constant signal (Little and Jones, 2011). The noise in the signal needs to be removed to identify the timing and volume of ebullitive events. The classic noise removal solvers, such as smoothing or filtering over a moving window, have several limitations when a signal can abruptly change, and these abrupt changes in pressure signals are what need to be allocated and preserved. From our field measurement data, the noise, which generally is symmetric and tailed due to temperature changes (Fig. 1), can be removed by the jump penalization method (Little and Jones, 2011). This jump penalization solver was chosen based on the observed results from 10 different noise removal solvers that were included in a "piecewise constant toolbox" (http://www.maxlittle.net/software/, last access: 11 May 2020). This toolbox implements algorithms for noise removal from 1D piecewise constant signals, such as total-variation and robust total-variation denoising, bilateral filtering, $k$-means, mean shift and soft versions of the same, jump penalization, and iterated medians (Little and Jones, 2011). After the noise is removed, the denoised data are composed of flat regions at different pressure levels and the boundary of those regions. The pressure levels are proportional to the volume of bubbles in the trap, and the locations of the jumps are the time when bubbles enter the trap. These events were detected by applying point-wise (first-order) differentiation calculations to the denoised data. The positive differentiates, with peak heights greater than 3 times the standard deviation of the baselines, were identified as ebullition events. A report data file including date, time of the ebullition event, and sizes of bubble was exported as a text file.

\subsection{Measuring $\mathrm{CH}_{4}$ and $\mathrm{CO}_{2}$ flux in the $\mathrm{AFC}$}

The AFC system presented in Duc et al. (2013) was improved by equipping the floating chamber with the previously described low-cost $\mathrm{CH}_{4}$ and $\mathrm{CO}_{2}$ sensors. To protect these sensors in high-humidity environments, their electronics boards were coated with polyurethane resin (Arathane 5750 or U1tifil 3000-010; details are in Sect. 1.1 Sensor coating in the Supplement). To prevent water splashing, the sensors were placed in a protected plastic box with holes for air throughflow mounted in the chamber. A detailed design is described in Bastviken et al. (2015); however, in this study the condensation protection sheet was not used. A rubber tube $(230 \mathrm{~mm} \times 65 \mathrm{~mm}$ inner tube with a straight valve stem, item no. 952932367600, https://www.esska.se/) was attached to the chamber to automatically open and close the chamber in the ventilation or accumulation phase by inflating and deflating the tube, respectively.

The $\mathrm{CH}_{4}$ sensor was configured as shown in Eugster and Kling (2012). It is powered with $5 \mathrm{Vdc}$, and its analog signals are recorded via the analog input of the data logger board (Duc et al., 2012). The $\mathrm{CO}_{2}$ sensor data, including $\mathrm{CO}_{2}$ concentration, relative humidity, and temperature, were transferred to the data logger via an I2C connection. The $\mathrm{CO}_{2}$ sensor is powered with $10 \mathrm{~V}$ dc. The $\mathrm{CO}_{2}$ sensors used in this study were prepared as described in Bastviken et al. (2015). In the recorded data file, in addition to the time stamp and sensor data, there is a chamber open/close marker. This helps to identify the accumulation and ventilation phases of the chamber. These data are postprocessed with a script (written in MATLAB, MathWorks, USA) to determine the fluxes during the chamber accumulation period.

Methane flux is determined based on the change in filtered $\mathrm{CH}_{4}$ sensor signals over an accumulation period. The filter is set to select a data period in which the variation of $\mathrm{RH}$ and temperature in the chamber is small enough to not affect $\mathrm{CH}_{4}$ sensor signals. The diffusive flux is estimated from the best linear increase in $\mathrm{CH}_{4}$ sensor signals without an ebullition event. Additional details are presented in the $\mathrm{CH}_{4}$ sensor calibration section. The $\mathrm{CO}_{2}$ sensor was tested previously for use in flux chambers to determine $\mathrm{CO}_{2}$ emission (Bastviken et al., 2015). The slope of the $\mathrm{CO}_{2}$ concentration, which is linearly changing in the time range and yields a value for $r^{2}$ that is higher than 0.98 , is extracted as the rate of $\mathrm{CO}_{2}$ emission per time. In our field study, the chamber is closed for $100 \mathrm{~min}$ and open for about $20 \mathrm{~min}$ for ventilation, and data from the sensors were output every $1 \mathrm{~min}$. The GHG flux is calculated using the following equation:

$F=\frac{\Delta \mathrm{C}}{\Delta t} \frac{P V}{R T} \frac{60 \times 10^{-6}}{A}$,

where $F$ is flux (e.g., $\mathrm{mol} \mathrm{m}^{-2} \mathrm{~h}^{-1}$ ), $\Delta \mathrm{C} / \Delta t$ is change in the GHG mixing ratio over time in the $\mathrm{FC}$ headspace $\left(\right.$ ppmv $\left.\min ^{-1}\right), P$ is atmospheric pressure (atm), $V$ is the FC volume $(6300 \mathrm{~mL}), \quad R$ is the gas constant $\left(82.0562 \mathrm{~mL} \mathrm{~atm} \mathrm{~K}^{-1} \mathrm{~mol}^{-1}\right), T$ is the temperature $(\mathrm{K}), A$ is surface area of the FC $\left(0.069 \mathrm{~m}^{2}\right), 60$ is a conversion factor from $\mathrm{min}^{-1}$ to $\mathrm{h}^{-1}$, and $10^{-6}$ is a conversion factor from ppmv to fractional mixing ratio measured in the gas. The flux time unit is in hours, representing a relevant time unit given the accumulation time of the chamber. As this study focuses on evaluating the sensor response to the change in the mixing ratio of $\mathrm{CH}_{4}$ and $\mathrm{CO}_{2}$ gases in the chamber in which the sensor signal is recorded every minute, $\Delta \mathrm{C} / \Delta t\left(\mathrm{ppmv} \mathrm{min}^{-1}\right)$ is used to demonstrate the response of the $\mathrm{CH}_{4}$ and $\mathrm{CO}_{2}$ sensors. 


\section{3 $\mathrm{CH}_{4}$ sensor test and calibration}

We tested three commercial TGS sensors for $\mathrm{CH}_{4}$ including TGS2611-E00, NGM 2611-E13, and a Panterra $\mathrm{CH}_{4}$ sensor. The TGS2611-E00 sensor is equipped with a filter to reduce the influence of interference gases such as ethanol, resulting in a more selective response to $\mathrm{CH}_{4}$ (Figaro, 2013). The NGM 2611-E13 is a precalibrated module for natural gas alarms, which is also based on the TGS2611E00 sensor. This module is prebuilt as a gas detector circuit with a standard pin connector. The Panterra $\mathrm{CH}_{4}$ sensor (PN-SM-GMT-A040A-W20A-05-R0- S0-E1-X0-I2-P0L2-J1-Z0, Panterra Neodym Technologies, Canada), which is based on a TGS2610 sensor, has been precalibrated by the manufacturer. We chose the specific sensor versions in dialog with sensor company representatives based on several criteria, including $\mathrm{CH}_{4}$ specificity, a sensitivity that was potentially high enough for our applications, price, and power consumption.

The responses of the $\mathrm{CH}_{4}$ sensor to concentration, temperature, and relative humidity ( $\mathrm{RH})$ in the chamber were studied, as well as the effect of hydrogen sulfide $\left(\mathrm{H}_{2} \mathrm{~S}\right)$, which is a potential inference gas released from some sediments. In a water tank in the laboratory, the AFC was set to close on the water surface for $100 \mathrm{~min}$ and open for $20 \mathrm{~min}$ for ventilation. Water temperature was regulated at different temperatures from 10 to $35^{\circ} \mathrm{C}$. In the temperature sensitivity experiment, the starting $\mathrm{CH}_{4}$ concentration was at atmospheric background levels (about $2 \mathrm{ppm}$ ), at which the temperature was varied. In the calibration experiments, at different temperature levels, about $10 \mathrm{~mL}$ of $\mathrm{CH}_{4} 1000 \mathrm{ppm}$ was injected into the $7 \mathrm{~L}$ chamber every 5 min until the AFC activated the ventilation process. About $5 \mathrm{~min}$ after the injection, a $10 \mathrm{~mL}$ gas sample from the chamber was withdrawn and injected into a gas chromatograph equipped with a flame ionization detector (GC-FID) to measure $\mathrm{CH}_{4}$ concentration to be compared with sensor-retrieved values. This test was repeated, and the headspace gas in the chamber was later circulated through a spectrometric gas analyzer (an FGGA with capacity to measure $\mathrm{CH}_{4}, \mathrm{CO}_{2}$, and $\mathrm{H}_{2} \mathrm{O}$; Los Gatos Research Inc.) for continuous $\mathrm{CH}_{4}$ and $\mathrm{CO}_{2}$ concentration measurements.

The $\mathrm{H}_{2} \mathrm{~S}$ interference experiment was carried out by injecting different volumes (from 2 to $637 \mathrm{~mL}$ ) of standard gas $\mathrm{H}_{2} \mathrm{~S}$ (100 ppm; Duotec AS, Denmark) into the test AFC. The chamber headspace gas was circulated through a biogas analyzer (Geotechnical Instruments, England) for measuring molecular oxygen $\left(\mathrm{O}_{2}\right)$ and $\mathrm{H}_{2} \mathrm{~S}$. These results were analyzed using the JMP Pro software and MATLAB to determine noise levels, quantitative flux determination limits, and a calibration equation.

\subsection{Field deployment and monitoring}

The field tests were performed on lakes at the Stordalen Mire, located near Abisko, Sweden (Wik et al., 2013). The floating control box was tied to a buoy, which was anchored to the lake bottom. The funnel and the chamber were attached to the control box at distances of 0.5 and $1 \mathrm{~m}$, respectively. The funnel and chamber were able to freely move around the anchor point within a radius of about $2 \mathrm{~m}$.

\section{Results}

\subsection{Bubble counter calibration experiment}

Calibrating the bubble counter revealed that the pressure sensor cannot detect the first $5 \mathrm{~mL}$ of gas in the trap due to the low accumulation pressure (Fig. S2). Therefore, to reach the detection limit of the pressure sensor, the automatic bubble counter was started (prime-pressurized) by pumping approximately $5 \mathrm{~mL}$ of air into the trap. This offset the $\mathrm{ABC}$ response in every measurement cycle. At pressures above this low-end threshold, the pressure sensor response showed a linear response to the volume of the gas captured in the trap. The upper threshold for a volume change that the trap can detect depends on the length of the extension PVC pipe: the longer the extension pipe, the wider the linear range of the bubble counter. Therefore, the ABC was programmed to end a bubble trap period by venting trapped gas before the extension pipe became completely filled with gas.

In stable conditions in the laboratory, the square root baseline signal (baseline noise) of the bubble trap at all pressure levels in the linear calibration curve is approximately $0.013 \mathrm{~V}$. The detection limit calculated from 3 times the noise $(0.039 \mathrm{~V})$ is equivalent to about $0.8 \mathrm{~mL}$. This means that our sensitivity is good enough to detect a bubble volume of $1 \mathrm{ml}$, corresponding to a bubble size that has high occurrence probability in lake systems (Wik et al., 2013). In data postprocessing, any incrementally increasing signal that was smaller than $0.04 \mathrm{~V}$ was therefore ignored. Field deployment data and the processed signal from a pressure sensor used to extract the bubble events are shown in Fig. 1. The pressure sensor signal measured in the trap was affected by air temperature, especially the diel temperature cycle. If there is no bubble in the trap, the pressure signals fluctuate around a certain median value (Fig. 2a). Small bubbles that enter the trap do not create a strong, incrementally increasing signal that was easily distinguished relative to the background noise. However, small bubbles still raised the pressure signal median, which can be detected by the jump penalization solver (Fig. 2b). Even if small individual bubbles are not resolved, their combined contribution to the trapped gas will be detected as increasing average differential pressure. The larger bubbles (around 3-4 mL) made stepwise increases clear in the pressure signal beyond the background noise, and the jump penalization solver was able to extract the median of this incrementally increasing pressure level. Larger bubbles therefore were determined with better resolution. Two cycles of bubble accumulation over a long-term field deployment 

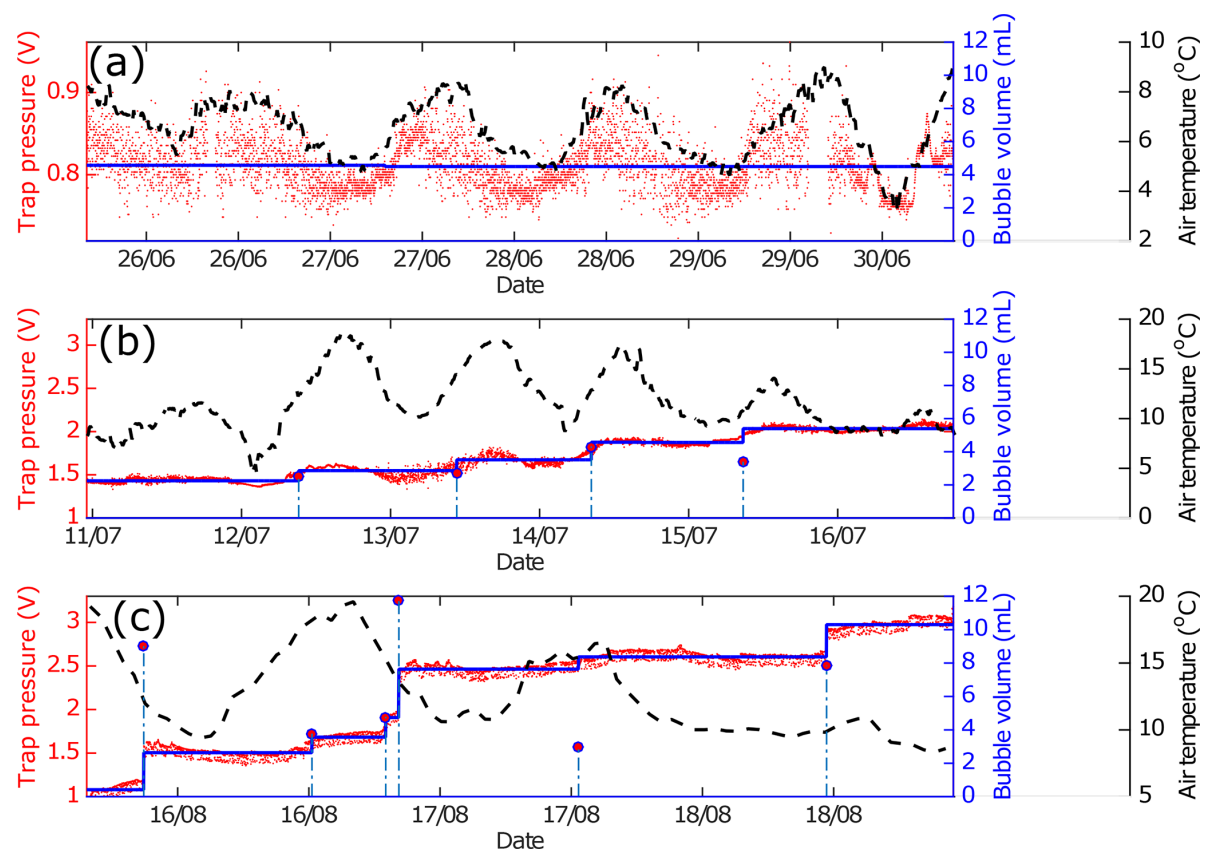

Figure 2. ABC pressure signal and air temperature over three field deployment periods. Red dots are trap pressure signals, blue lines are the denoised pressure sensor signal, stem plots (dashed vertical lines with a red circle on top) are bubble events which were detected from the stepwise increase in denoised signals, and black dashes are air temperature. (a) Sample period with no bubbles entering the trap, (b) sample period with small bubbles entering the trap, and (c) sample period with both big and small bubbles entering the trap.

from two tested devices show that a wide variability of bubble sizes can enter the trap, from small bubble sizes $(1-2 \mathrm{~mL})$ whose signal is buried in the noise to a large bubble ( $>6 \mathrm{~mL}$ ) that creates a large pressure signal compared to the background (Fig. 3). If bubbles entered the trap and were large enough to activate the venting mechanism during a nonlogging period (in the present system this would require a total bubble volume of $>28 \mathrm{~mL}$ ), it was missed in the logged data file. However, no single-bubble events larger than this threshold were experienced in the field tests so far.

\section{2 $\mathrm{AFC} \mathrm{CH}_{4}$ sensor calibration experiment}

The response of the $\mathrm{CH}_{4}$ sensor to changing temperature, $\mathrm{RH}$, and $\mathrm{CH}_{4}$ concentration (around 2 ppmv) when the chamber closed on the water surface is shown in Fig. 4. In the first few minutes after chamber closure, the temperature and RH changed quickly in the chamber, causing a drift in the $\mathrm{CH}_{4}$ sensor signal, but once temperature and $\mathrm{RH}$ stabilized the sensor responded in a predictable way to changes in $\mathrm{CH}_{4}$ concentration inside the chamber. After temperature and $\mathrm{RH}$ stabilization occurred in the chamber, we determined the detection limit of our instrument for $\mathrm{CH}_{4}$ fluxes based on the noise of the $\mathrm{CH}_{4}$ sensor. In these blank experiments, the $\mathrm{RH}$ was always in the range of $60 \%-90 \%$, which is within the sensor's $\mathrm{RH}$ operating range. The operation of the $\mathrm{CH}_{4}$ sensor includes heating it to a high temperature to detect combustible gases; therefore, the temperature inside the sensor box is always higher than the water temperature. The temperature sensor of the ELG $\mathrm{CO}_{2}$ sensor measured the change in temperature inside the sensor box over the water temperature. The noise over a whole accumulation period (100 min) was about $2.44 \pm 1.21 \mathrm{mV}$. A minimum accumulation rate limit is calculated as 5 times the noise, or about $12.2 \mathrm{mV}$. Therefore, we calculated the $\mathrm{CH}_{4}$ concentration increase that generated a $\mathrm{CH}_{4}$ sensor signal of $12.2 \mathrm{mV}$ to be equivalent to $5.25 \mathrm{ppm}$ and used this to calculate a minimum detectable $\mathrm{CH}_{4}$ flux. In an accumulation period, the accumulation rate detection limit of this sensor embedded in the chamber is $5.25 \mathrm{ppm}$ per $100 \min \left(0.0525 \mathrm{ppm} \mathrm{min}^{-1}\right)$.

At all temperatures $\left(10,20,25\right.$, and $\left.30^{\circ} \mathrm{C}\right)$, the three $\mathrm{CH}_{4}$ sensor signals were well correlated to $\mathrm{CH}_{4}$ concentration, but these correlation lines had different intercepts depending on water temperature (Fig. S3a-c). The absolute concentrations measured by the sensors were affected by temperature and $\mathrm{RH}$ and were not suitable for use. To study $\mathrm{CH}_{4}$ flux, we instead used the relative change in $\mathrm{CH}_{4}$ concentration over time from $5 \mathrm{~min}$ after chamber closure to avoid the periods with the largest changes in temperature and RH. Accordingly, the differential $\mathrm{CH}_{4}$ sensor signal (d0_ $\mathrm{CH}_{4}$ sens), which is the difference between the current measurement and the initial measurement point $5 \mathrm{~min}$ after the chamber closed on the water surface, was used instead of the raw output signal from the sensor. Indeed, the differential $\mathrm{CH}_{4}$ sensor signal was less sensitive to temperature and had a linear response $\left(r^{2}=0.98 ; p<0.001\right)$ across the studied temperatures 

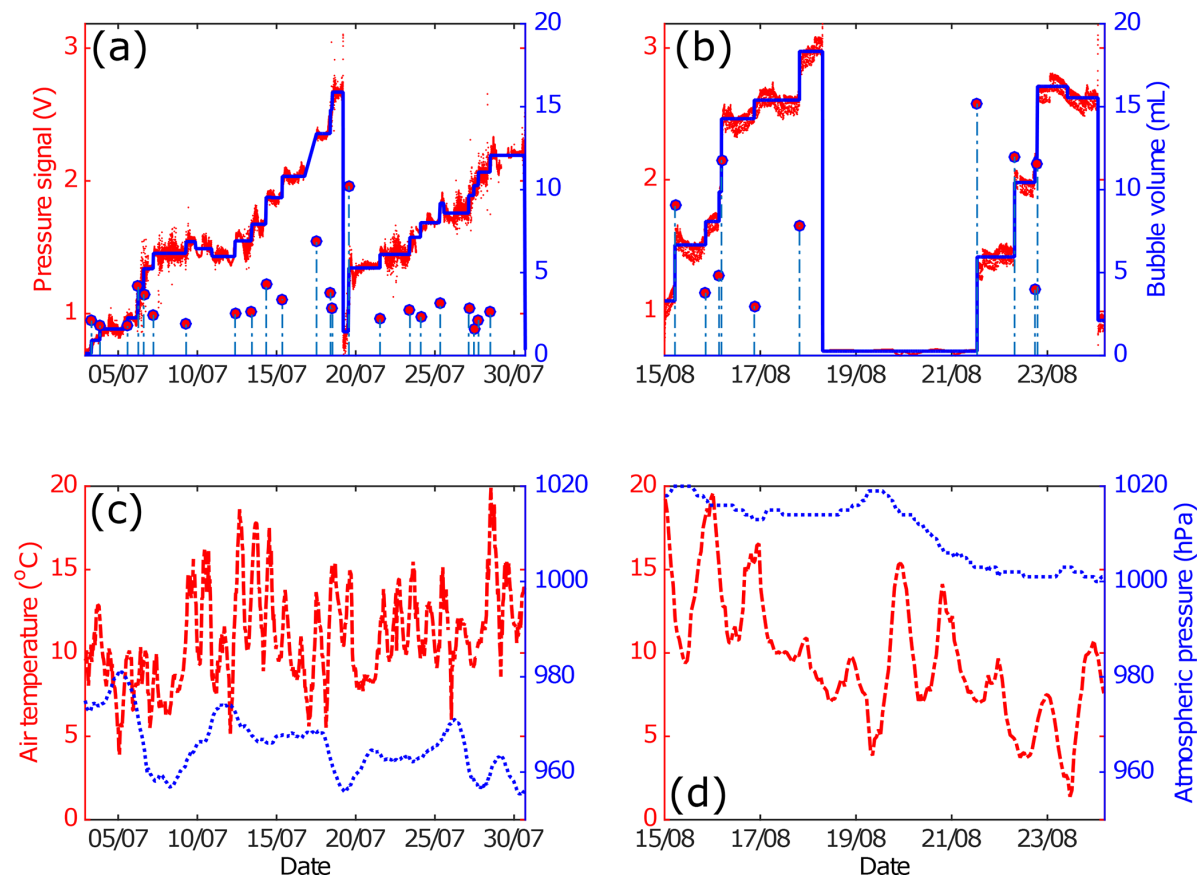

Figure 3. Two measurement periods of an ABC deployed in Mellersta Harrsjön, Stordalen Mire, Abisko, in 2015. (a, b) Sample period when bubbles entering the trap were detected from the denoised pressure signal. Red dots are trap pressure signals, blue lines are the denoised pressure sensor signal, and stem plots (dashed vertical lines with a red circle on top) are bubble events. (c, d) Air temperature and atmospheric pressure from an onshore weather station during the same sample period. Red dashes are air temperature and blue dots are atmospheric pressure.
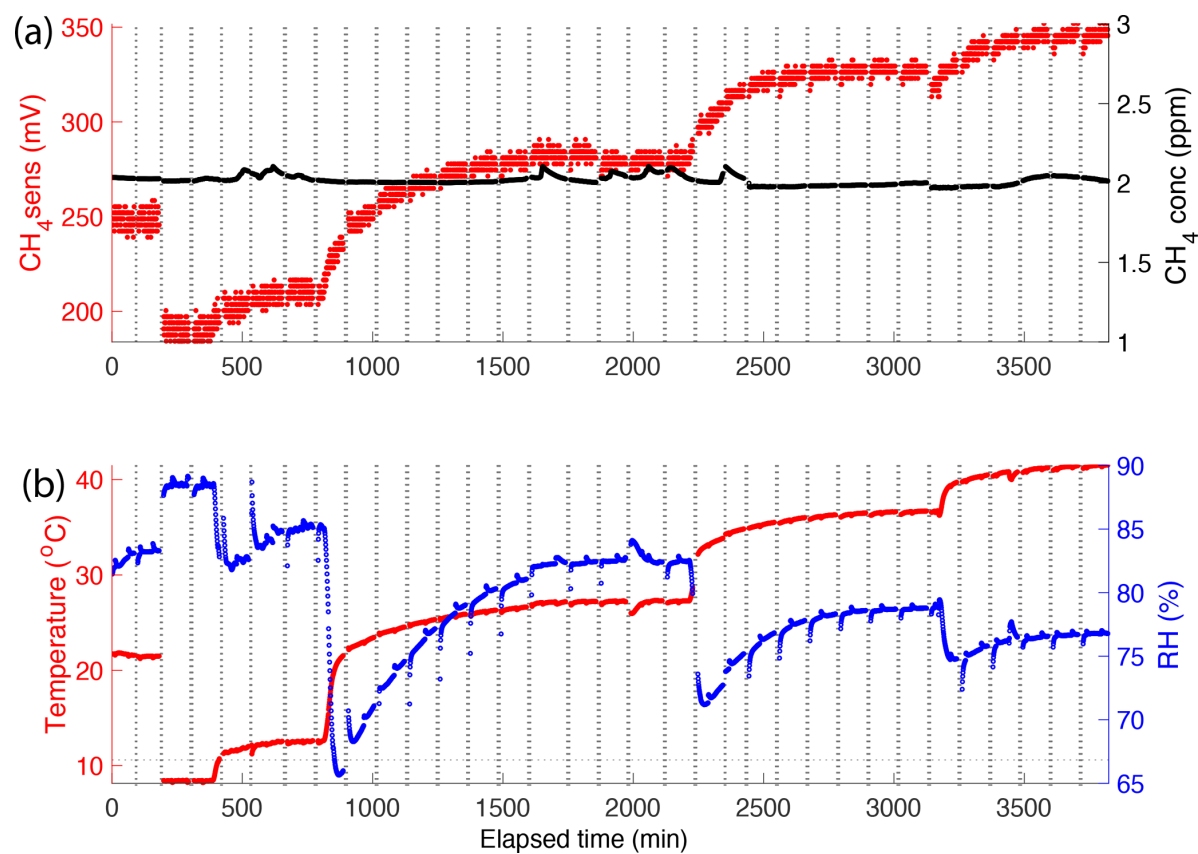

Figure 4. Methane ( $\mathrm{mV}$ response and concentration), temperature $\left({ }^{\circ} \mathrm{C}\right)$, and $\mathrm{RH}(\%)$ sensor responses in the initial phase of the sensor test experiment in which the temperature of the water tank was regulated in the range of 5 to $35^{\circ} \mathrm{C}$. (a) $\mathrm{CH}_{4}$ sensor signal and actual $\mathrm{CH}_{4}$ concentration around 2 ppm and (b) temperature and RH in the chamber over the experimental period. Dotted vertical lines denote periods when the chamber was opened for ventilation. 


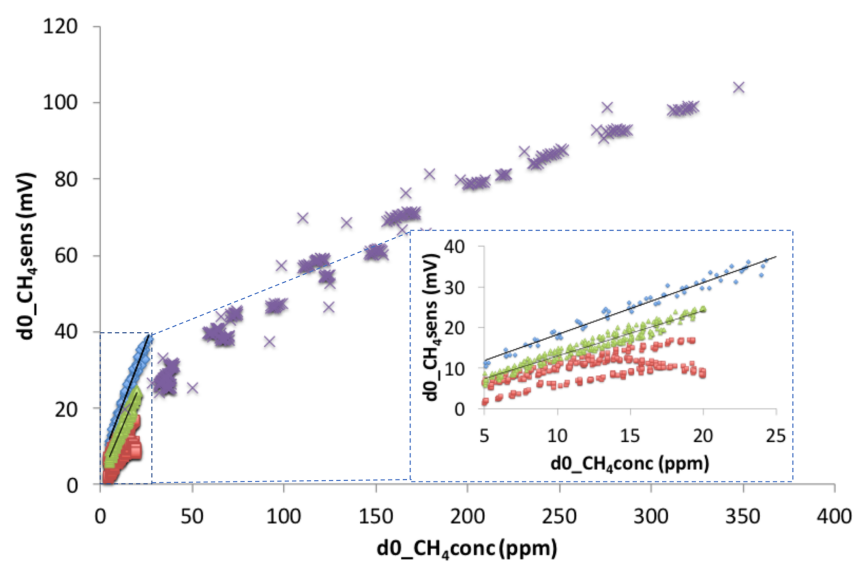

Figure 5. Response curves of the $\mathrm{CH}_{4}$ sensor's responses at all experimental water temperatures from 10 to $30^{\circ} \mathrm{C}$ versus the change in $\mathrm{CH}_{4}$ mixing ratio measured by GC-FID or a Los Gatos Research FGGA greenhouse gas analyzer ( $\left.\mathrm{d} 0 \__{-} \mathrm{CH}_{4} \mathrm{conc}\right)$. The blue diamonds, green triangles, purple crosses $\left(\Delta, x\right.$ : for a $\mathrm{CH}_{4}$ concentration higher than $25 \mathrm{ppm}$ ), and red squares represent the change in the $\mathrm{CH}_{4}$ sensor signal over time from the chamber closure (d0_CH 4 sens) of the TGS2611-E00, NGM2611-E13 and the Panterra sensor, respectively. See text for details.

(Fig. 5). In this test, the variability in the temperature and $\mathrm{RH}$ were in the ranges of $2{ }^{\circ} \mathrm{C}$ and $5 \%$, respectively, while $\mathrm{CH}_{4}$ concentration increased from atmospheric, or about $2 \mathrm{ppm}$, to $25 \mathrm{ppm}$. The standard least-square fit model was applied to d0_ $\mathrm{CH}_{4}$ sens as a model response and the changing $\mathrm{CH}_{4}$ concentration, temperature, and RH as model effects. The result showed that the variability of temperature $(p=0.038)$ and $\mathrm{RH}(p=0.867)$ has less influence on the $\mathrm{CH}_{4}$ sensor response compared to the $\mathrm{CH}_{4}$ concentration $(p<0.001)$. This reveals that these $\mathrm{CH}_{4}$ sensors can be used to measure $\mathrm{CH}_{4}$ flux when the temperature and $\mathrm{RH}$ conditions are stable in the chamber.

The effect of temperature and $\mathrm{RH}$ can be corrected for in the response of the sensor using an algorithm developed by Eugster and Kling (2012), but this was not applied in our study because we were not able to simulate the natural variations of outdoor temperature and $\mathrm{RH}$ conditions in our control experiment. Therefore, periods with stable temperature and RH were used, and the calibration curve for the TGS2611-E00 $\mathrm{CH}_{4}$ sensor in our application was the average linear response of $\mathrm{d} 0{ }_{-} \mathrm{CH}_{4}$ sens versus the change in $\mathrm{CH}_{4}$ concentration (d0_ $\mathrm{CH}_{4}$ conc) without temperature and RH correction (Fig. 5):

d0_CH 4 sens $=1.256 \times$ d0_ $\mathrm{CH}_{4} \mathrm{conc}+5.871$,

where d0_ $\mathrm{CH}_{4}$ sens is the voltage change in the $\mathrm{CH}_{4}$ sensor in $\mathrm{mV}$, and $\mathrm{d} 0 \_\mathrm{CH}_{4}$ conc is in parts per million by volume. Compared with this sensor, calibration results showed that the precalibrated Figaro NGM2611-E13 module has about the same response to the change in $\mathrm{CH}_{4}$ concentration at all temperatures. The NGM2611-E13 had a regression equation as follows:

d0_CH 4 sens $=1.116 \times$ d0_ $\mathrm{CH}_{4} \operatorname{conc}+1.771$.

The Panterra $\mathrm{CH}_{4}$ sensor showed a different response at different temperatures (Fig. 4). Its calibration lines had different responses at 10 and $15^{\circ} \mathrm{C}$, and its $\mathrm{d} 0 \_\mathrm{CH}_{4}$ sens had a negative response when $\mathrm{d} 0{ }_{-} \mathrm{CH}_{4}$ conc was higher than $15 \mathrm{ppm}$ at 20 and $30^{\circ} \mathrm{C}$.

In the $\mathrm{H}_{2} \mathrm{~S}$ interference test, the injected volume of the standard gas (100 ppmv) increased from 2 to $637 \mathrm{~mL}$. The biogas analyzer did not detect any $\mathrm{H}_{2} \mathrm{~S}$ even when the estimated $\mathrm{H}_{2} \mathrm{~S}$ concentration in the chamber was $9 \mathrm{ppm}$. This level is close to the detection limit of the instrument, and given the minimum analytical uncertainty of $\pm 10 \mathrm{ppm}$, it is likely that $\mathrm{H}_{2} \mathrm{~S}$ was present in high enough amounts to affect the $\mathrm{CH}_{4}$ sensors. During the $\mathrm{H}_{2} \mathrm{~S}$ addition, the $\mathrm{CH}_{4}$ sensor signal increased to more than 5 times baseline noise; therefore, $\mathrm{H}_{2} \mathrm{~S}$ was considered to affect the sensor response in agreement with sensor producer tests.

\section{3 $\mathrm{CH}_{4}$ and $\mathrm{CO}_{2}$ flux with the $\mathrm{AFC}$}

The pilot field deployment of the AFC-embedded $\mathrm{CH}_{4}$ and $\mathrm{CO}_{2}$ sensors showed that the system was effective for measuring the variation of $\mathrm{CH}_{4}$ and $\mathrm{CO}_{2}$ concentration in the chamber over time (Fig. 6a-c). The automatic mechanism developed to close the chamber for flux measurements and open the chamber for ventilation periods/phases helped to reduce condensation and allowed for a linear response of the $\mathrm{CO}_{2}$ sensor (Fig. 6b). This is an improvement over past work and allows for the sensor to be deployed in the field for long time periods. There was a situation when the chamber was closed on the water surface for a whole night due to a low battery. As a result, the saturated RH in the chamber became higher than $100 \%$ and caused condensation and malfunction in the sensor until drying (discussed in Bastviken et al., 2015). After two ventilation cycles the $\mathrm{CO}_{2}$ sensor dried, and the baseline decreased to the normal linear response range. The $\mathrm{CO}_{2}$ sensor responses were not affected by temperature and $\mathrm{RH}$ in our experiment. Therefore, $\mathrm{CO}_{2}$ flux is determined from the slope of the best linear response data in an accumulation period.

During measurement periods, right after ventilation, $\mathrm{CO}_{2}$ concentrations in the chamber are supposed to be equal to the atmospheric $\mathrm{CO}_{2}$ concentration above the lake surface. These initial $\mathrm{CO}_{2}$ concentrations varied within a range of 516-1179 ppmv, with higher mixing ratios during nighttime. Because the chamber ventilation time was early in the development and adjusted to allow complete ventilation of the chamber headspace, the elevated starting concentrations may reflect actual concentrations if stable atmospheric conditions resulted in a near-ground buildup of $\mathrm{CO}_{2}$ released from the lake and the surrounding mire ecosystem. 

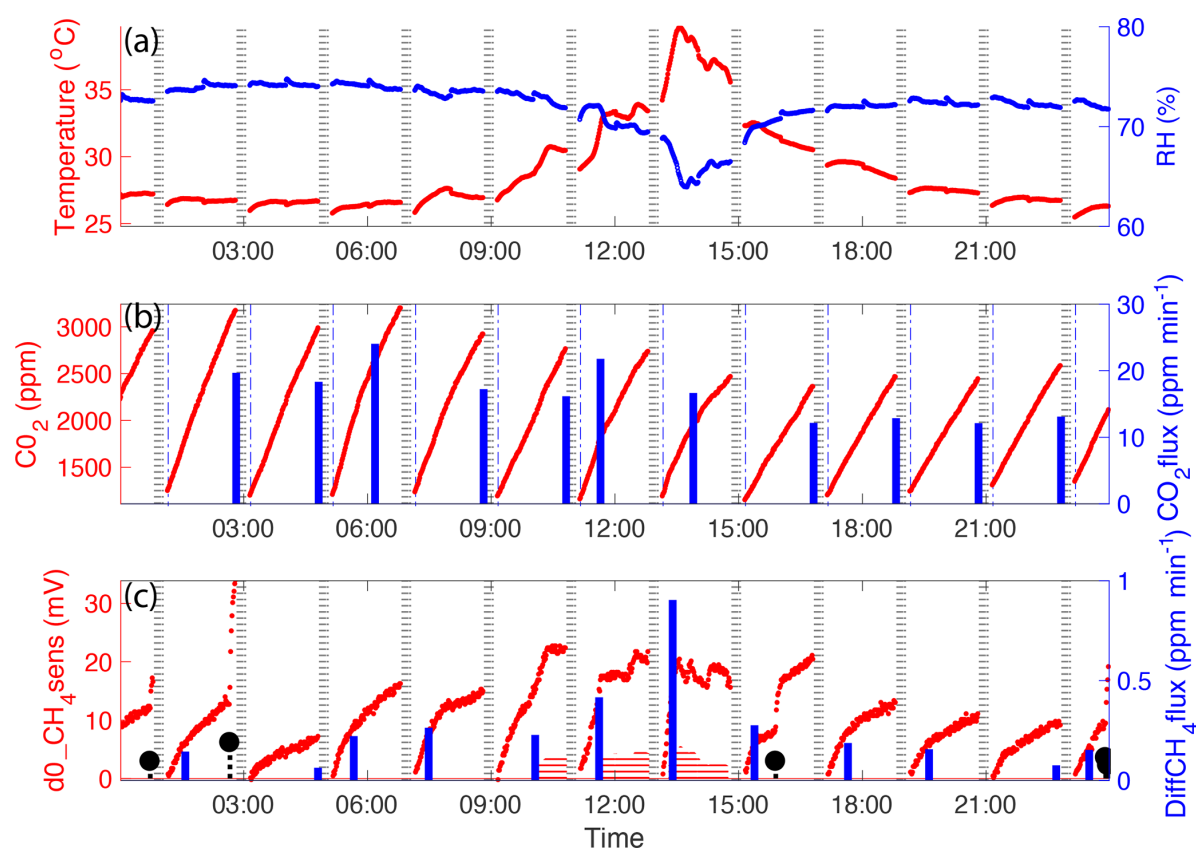

Figure 6. Example of 1 day of automatic flux chamber (AFC) measurements covering 11 accumulation periods. (a) Scatter plot of temperature (left axis, red) and $\mathrm{RH}$ (right axis, blue) in the chamber. (b) Scatter plot of $\mathrm{CO}_{2}$ concentration measured by an $\mathrm{ELG} \mathrm{CO}_{2}$ sensor (left axis) and bar plot of $\mathrm{CO}_{2}$ fluxes calculated from slopes of the changing $\mathrm{CO}_{2}$ concentration in the time range marked from the vertical dash-dot line to bar plot location (right axis). (c) Scatter plot of $\mathrm{CH}_{4}$ sensor signal (left axis) and bar plot of $\mathrm{CH}_{4}$ fluxes (right axis) calculated from the best linear data range when $\mathrm{d} 0 \_\mathrm{CH}_{4}$ sens values were in the linear calibration range (less than $30 \mathrm{mV}$ ). Temperature and $\mathrm{RH}$ changes are less than $2{ }^{\circ} \mathrm{C}$ and $5 \%$. Red shaded periods indicate sampling when temperature and $\mathrm{RH}$ affected the gas sensor response, and these data could therefore not be used in the flux calculation. In the event of an ebullition event, the flux calculation is made with data taken prior to that event. Ebullition events are marked by the black stem plot.

The field deployments revealed that there were many periods in which temperature and $\mathrm{RH}$ conditions of the chamber were stable enough (Fig. 6a) for the Figaro $\mathrm{CH}_{4}$ sensors to adequately measure the change in the $\mathrm{CH}_{4}$ mixing ratio in the chamber. In cases where temperature and $\mathrm{RH}$ varied a lot, the data processing script determined periods of data when the variation of temperature and $\mathrm{RH}$ was less than $2{ }^{\circ} \mathrm{C}$ and $5 \%$, respectively, defining periods for which $\mathrm{CH}_{4}$ sensor data could be reliably evaluated. If ebullitive $\mathrm{CH}_{4}$ entered the chamber headspace, there was a clear positive change in the sensor signal output. This was easily identified as a stepwise increase in the $\mathrm{CH}_{4}$ sensor signal over a very short time. This signal identified the type of ebullitive flux that could be measured over that chamber closure period. For diffusive $\mathrm{CH}_{4}$ flux measurements, the $\mathrm{d} 0{ }_{-} \mathrm{CH}_{4}$ sens data, with a sensor response of less than $30 \mathrm{mV}$ (within linear calibration range) and without a stepwise jump, were scanned for a data range with best linearly adjusted $r^{2}$. For diffusive flux estimation, the $\Delta \mathrm{C} / \Delta t$ (ppmv $\mathrm{min}^{-1}$ ) in Eq. (1) is calculated using the last $\mathrm{d} 0{ }_{-} \mathrm{CH}_{4}$ sens point in this linear range, in which d0_CH 4 sens is converted to d0_ $\mathrm{CH}_{4}$ conc (ppmv) according to Eq. (2), and its location in time since the chamber was closed is calculated for the measurement period (every minute). The manually collected gas samples in the field and the $\mathrm{CH}_{4}$ mixing ratio change over time (ppmv per unit time) in the chamber headspace, determined from the sensor response, which showed a strong linear relationship with a deviation of less than $15 \%$ (Fig. 7). The ebullitive $\mathrm{CH}_{4}$, which was detected by the $\mathrm{CH}_{4}$ sensor in the AFC, was not concentration-quantified in this study focusing on the relative changes in the methane sensor in the low range because $\mathrm{CH}_{4}$ sensor response to ebullition events was usually out of the linear calibration range.

\section{Discussion}

\subsection{Automated ebullition measurements using pressure sensors}

Deploying pressure sensors to determine the timing of ebullition events and to measure the bubble volumes has been thoroughly tested by Varadharajan et al. (2010). Our bubble trap introduces a way to automatically reset the system after being full of gas that allows for long-term deployment with minimum maintenance effort. This design idea is similar to the automatic bubble traps in Maeck et al. (2014). Further, via the jump penalization noise removal method, bubble events can be detected despite the noise caused by changes in air 


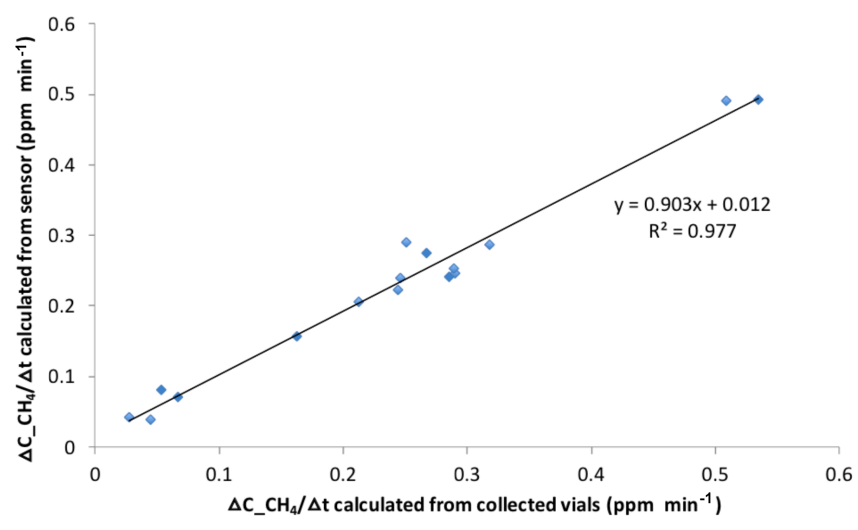

Figure 7. Methane accumulation rates calculated from an NGM2611-E13 $\mathrm{CH}_{4}$ sensor signal compared to accumulation rates calculated from the $\mathrm{CH}_{4}$ mixing ratio in gas samples collected at the start and end of accumulation periods.

temperature affecting the bubble volumes and therefore the differential pressure. It is important that the $\mathrm{ABC}$ is gastight. This is not a simple requirement, especially because the trap is built from plastic materials meant to be easily disconnected for portability and is exposed to the outdoor environment. After a long deployment time, leaks were occasionally observed at the assembly joint of the pressure sensor. So far, if a trap leak occurs, the pressure is lower than the priming pressure threshold, which was set to trigger a warning indication to the host server controller on the lakeshore. It can be fixed by applying glue to the leak site. The detection limit of the differential pressure measurement, in our case corresponding to $1-2 \mathrm{~mL}$ gas, depends on the shape of the cylinder where the bubbles accumulate (Maeck et al., 2014; Varadharajan et al., 2010). Therefore, the longer and narrower a cylinder is, the lower the detection limit will be. This leads to a trade-off in which the more sensitive systems become too tall for deployment in shallow waters, which often have proportionally higher ebullition rates (Wik et al., 2013). Our detection limit was chosen to allow deployment in shallow water with a trap height of about $0.5 \mathrm{~m}$. The recent study using optical sensors in an open path funnel (Delwiche and Hemond, 2017) that makes a shorter trap suggests an alternative and interesting design for ebullition studies, which could be combined with the present sensor approach to also quantify $\mathrm{CH}_{4}$ content in the bubbles.

\subsection{Automatic measurement of $\mathrm{CH}_{4}$ and $\mathrm{CO}_{2}$ during chamber fluxes}

In our application, the low-cost $\mathrm{CH}_{4}$ and $\mathrm{CO}_{2}$ sensors can be used to measure changing $\mathrm{CH}_{4}$ and $\mathrm{CO}_{2}$ concentrations. It is a direct approach to measure $\mathrm{CH}_{4}$ and $\mathrm{CO}_{2}$ flux from a defined-footprint area on the timescale of minutes to hours, extending over long-time periods given a suitable power supply. The chamber captures both ebullition and diffusion fluxes. Ebullition events are marked by abrupt changes in the response of the $\mathrm{CH}_{4}$ sensor and therefore can be identified readily. The diffusive flux is identified by the gradual change in $\mathrm{CH}_{4}$ and $\mathrm{CO}_{2}$ concentration over time. We did observe ebullition events in the chamber during deployment periods, which is in support of the previous indications that ebullition typically accounts for a large share of the open-water flux (Fig. 6c). However, since we did not calibrate the sensor for high concentrations, we could not determine the flux rate observed during these events. This remains a challenge for future work.

To study diffusive fluxes, it is important to measure the change in gas concentrations during a short period of time right after the chamber closes. This requires a gas sensor that can measure at near-ambient gas concentrations. The $\mathrm{CH}_{4}$ injection experiment showed that both of the Figaro $\mathrm{CH}_{4}$ sensors have sensitivity at low parts-per-million mixing ratios and yield a linear response from ambient at about $2 \mathrm{ppm}$ up to 25 ppm. The TGS2611-E00 and NGM2611-E13 have small differences in their response (slope) in the linear range; however, their responses to experimental conditions are overall very similar because they use the same sensor base. In outdoor field conditions, after closing on the water surface, it takes some time for temperature and RH in the chamber to stabilize. The rejection of data from the initial $5 \mathrm{~min}$ of measurements is important to select an initial $\mathrm{CH}_{4}$ sensor data point when the temperature and $\mathrm{RH}$ have become more stable and to minimize the influence of these confounding factors on the relative change in $\mathrm{CH}_{4}$ sensor signal. An obvious data interpretation improvement would need to modify the length of the initial period during which data are not used and thus the actual time it takes to reach stable enough relative humidity and temperature instead of having the static 5 min period used here for simplicity.

It is possible that the sensors can be used outside the range reported here by developing other calibration curves. In any case, we recommend adjusting the AFC accumulation time to the effective range of the sensor. Alternatively, flux calculation can be based on data within the linear range only in the postprocessing of the data. Calibration of the Figaro $\mathrm{CH}_{4}$ sensor is recommended for each individual sensor. The response slopes of different sensors could deviate up to $12 \%$. For practical reasons, if flux estimation with an error tolerance of $\pm 20 \%$ is accepted (Wik et al., 2016a), one general calibration line can be obtained from a calibration of at least five $\mathrm{CH}_{4}$ sensors for statistical representativeness. In our study, the calibration line was obtained from the calibration experiment of eight sensors. Due to the effect of temperature and $\mathrm{RH}$, the calibration curve should be based on calibration data at different water temperatures that span anticipated field conditions. Compared to Duc et al. (2012), who used the Panterra $\mathrm{CH}_{4}$ sensor, the Figaro $\mathrm{CH}_{4}$ sensor gave more reliable and robust flux measurement results under field conditions. 
The $\mathrm{H}_{2} \mathrm{~S}$ interference test revealed that $\mathrm{H}_{2} \mathrm{~S}$, a corrosive gas which can be released from anoxic sediments in sulfurrich systems, may interfere with sensor response. Therefore, extra care and thorough data validation are suggested when applying the sensors in sulfur-rich environments. In addition, this $\mathrm{CH}_{4}$ sensor response is based on the reaction between $\mathrm{O}_{2}$ in air and reductant (flammable) gases; therefore, any change in concentrations of either $\mathrm{O}_{2}$ or reductant gases could interfere with the signal of the sensor. This $\mathrm{CH}_{4}$ sensor can combust a small amount $\mathrm{CH}_{4}$ gas (about $0.0041 \mathrm{ppmv} \mathrm{min}^{-1}$ ), which needs to be considered when the $\mathrm{CH}_{4}$ flux is low (near the sensor's detection limit of $0.0525 \mathrm{ppmv} \mathrm{min}^{-1}$ in our application) and the chamber accumulation time is very long.

One limitation of the $\mathrm{CH}_{4}$ sensor is its power consumption. While the $\mathrm{CO}_{2}$ sensor can be activated once per minute (or at other desired time intervals), the $\mathrm{CH}_{4}$ sensor needs to be heated at all times. In our case, these systems were deployed at high latitudes in the summer, and the battery was recharged by a $13 \mathrm{~W}$ solar panel. If the weather was cloudy for 4 to 5 days in a row, the battery voltage fell below $10.5 \mathrm{~V}$. At this point, the system automatically turns off until the battery is recharged. In 2017, the replacement lithium-ion battery (12 V $55 \mathrm{Ah}$; Power Pack LS 55) helped to keep the system working continuously during longer time periods and reduced the weight of the control box.

Over our deployment time, there were several chambers that were either submerged or turned over. The chambers were submerged because the rubber inner tube degraded due to UV exposure over a long period of time, generally after about two sampling seasons. This problem was solved by covering the inner tube with aluminum foil or by changing to the gas delivery flow scheme shown in Fig. S9 ("no sink AFC"). With this new flow design, the air in the floating control box was pumped into the rubber inner tube until the inner tube was full. When the pressure inside the rubber inner tube is more than $1 \mathrm{psi}$, the check valve opens and the excess air is blown into the chamber to refresh its headspace. Compared with the previous gas flow design, in which the air is withdrawn from the chamber, this new gas flow scheme will prevent pressure from building up in the chamber during the ventilation process; hence, even in a situation where the chamber cannot open due to failure of the rubber inner tube, the chamber will not sink. With this configuration, the sample array presented in Duc et al. (2013) cannot be used. The strong correlation between grab samples and the sensors (Fig. 7) allows us, however, to capture the high temporal fluxes and skip the labor-intensive process of analyzing grab samples. Manual grab samples should, however, be taken periodically as a cross check of the sensor response. The other problem of chamber flipping was caused by wind suddenly changing its direction during chamber ventilation process. To prevent this flipping, the opening side of the chamber was attached to two floating anchors (called antiflipping anchors) (Fig. S10). With this improvement, there have been no cham- ber flips during tests with maximum wind speeds of about $7 \mathrm{~m} \mathrm{~s}^{-1}$

\subsection{Challenges when networking measurement systems remotely}

One goal of our project was to develop an active wireless sensor network in which a small low-cost Raspberry Pi computer on the lakeshore communicates with many flux chambers and bubble traps (called clients) by $2.4 \mathrm{GHz}$ XBee radio transmitter modules. The communication is to synchronize real date, time, and working parameters; to check client status; and to receive data from clients. The sampling sensor data rate so far is constrained to maintain the DigiMesh network working with minimum labor effort. Under harsh weather conditions (rain and hard wind), radio communication is easily broken, and it can take some minutes to re-establish depending on the distance and number of the clients. During this offline period, the limited memory buffer of the client data logger did not allow a very high measurement frequency. As a result of this limitation, a $1 \mathrm{~min}$ data sampling interval was used to provide stability for long-term deployment. In spite of our low measurement frequency, the results show that the system is still able to capture relative changes in $\mathrm{CH}_{4}$ concentration adequately. This situation is different from applications that aim for accurate absolute concentrations in ambient air, and for such applications a high measurement frequency is more important to cancel out sensor noise in data processing than in our flux chamber application. In our AFC system, a higher frequency of data can be recorded in a local 2 GB SD memory card on the data logger of each trap if desired.

In our study, the traps were on the lake surface, which was usually lower than ground level and surrounded by trees and plants. Over the study season, the growth of vegetation on the lakeshore can potentially block the line of sight between the host controller and the traps on the lake, which can hamper radio communication. To guarantee radio communication, at least one client (i.e., chamber system) was placed at a strategic location which had a clear line of sight to the host controller. Within the DigiMesh network, XBee modules can form a self-configuring, self-healing, wireless peer-to-peer network with other data loggers in radio range. Therefore, the host controller does not necessarily need to have direct line-of-sight communication with all of the traps on the lake surface. If some of the traps are out of the controller's direct range, they should automatically pass their messages through closer clients. Therefore, it is important to keep a robust network topology.

Occasional errors within this network still occur, probably due to the high-humidity environment around the clients and variable weather conditions, temperature, and humidity (Luomala and Hakala, 2015). This could cause failure in the transfer of some initial data packets in the data file or break the communication with clients. Hence, software for this system was developed to address these errors. For example, all 
the data packets were encoded, so the missing data can be easily identified in data postprocessing, and the host controller keeps searching to re-establish communication with "lost" clients. Details of the wireless communication protocol and host controller design are presented in the Supplement.

\section{Conclusions}

Resolving diffusive and ebullitive GHG fluxes at the airwater interface in a well-defined footprint area is needed so that we can accurately represent open bodies of water like lakes and streams in global $\mathrm{CH}_{4}$ and $\mathrm{CO}_{2}$ budgets. With the benefit of low-cost technology, we have modified simple flux chambers and bubble traps to function automatically with wireless remote monitoring and control via an internet browser. These traps are equipped with not only the sensors to monitor the fluxes in high temporal resolution but also the electromechanical hardware to do complex actions in the field such as venting traps and collecting gas samples (if needed). This is our first attempt to integrate several low-cost technologies to make a device for measuring GHG emissions from lakes with the data updated online in real time. This device, as an open-source technology for nonprofit academic study, can hopefully contribute to studies of GHG emission from aquatic environments in remote and logistically difficult areas.

Data availability. The data associated with this work are stored on the data repository site of the Bolin Centre at Stockholm University (https://bolin.su.se/data/stordalen-ghg-sensors-2015-iot, last access: 1 July 2020) (Duc et al., 2020).

Supplement. The supplement related to this article is available online at: https://doi.org/10.5194/hess-24-3417-2020-supplement.

Author contributions. NTD developed the hardware and software, designed the AFC-ABC system, conducted the study, developed the MATLAB script, processed data, and cowrote the manuscript. SS developed the hardware and core software, designed the wireless data logger and web server, and contributed to the manuscript. MW conducted the study and contributed to the manuscript. PC, DB, and RKV gave advice through all stages of the study, contributed funding, and cowrote the manuscript. All authors discussed the results and commented on the manuscript.

Competing interests. The authors declare that they have no conflict of interest.
Acknowledgements. This research was supported through a postdoctoral fellowship funded by the University of New Hampshire. The 2014 and 2015 field deployments were supported through two US National Science Foundation (NSF) grants to Ruth Varner MacroSystems Biology (EF no. 1241937) and the Northern Ecosystems Research for Undergraduates program (NSF REU site EAR no.1063037) - and by funding from the Swedish Research Council (VR) to David Bastviken and Patrick Crill (grant no. 201200048). Work time for data analysis and manuscript preparation was also financed by the VR (grant no. 2016-04829), FORMAS (grant no. 2018-01794), VINNOVA (grant no. 2015-03529), and the European Research Council (ERC) under the European Union's Horizon 2020 research and innovation program (grant agreement no. 725546).

Financial support. This research has been supported by the US National Science Foundation (NSF) (MacroSystems Biology, EF no. 1241937, and the Northern Ecosystems Research for Undergraduates program, NSF REU site EAR no.1063037), the Swedish Research Council (VR) (grant nos. 2012-00048 and 2016-04829), the European Research Council (ERC) (grant no. 725546), and the VINNOVA (grant no. 2015-03529).

Review statement. This paper was edited by Anas Ghadouani and reviewed by Werner Eugster and Maciej Bartosiewicz.

\section{References}

Anderson, D. E., Striegl, R. G., Stannard, D. I., Michmerhuizen, C. M., McConnaughey, T. A., and LaBaugh, J. W.: Estimating lakeatmosphere $\mathrm{CO}_{2}$ exchange, Limnol. Oceanogr., 44, 988-1001, https://doi.org/10.4319/lo.1999.44.4.0988, 1999.

Bastviken, D., Cole, J., Pace, M., and Tranvik, L.: Methane emissions from lakes: Dependence of lake characteristics, two regional assessments, and a global estimate, Global Biogeochem. Cy., 18, GB4009, https://doi.org/10.1029/2004GB002238, 2004, 2004.

Bastviken, D., Tranvik, L. J., Downing, J. A., Crill, P. M., and Enrich-Prast, A.: Freshwater Methane Emissions Offset the Continental Carbon Sink, Science, 331, p. 50, https://doi.org/10.1126/science.1196808, 2011.

Bastviken, D., Sundgren, I., Natchimuthu, S., Reyier, H., and Gålfalk, M.: Technical Note: Cost-efficient approaches to measure carbon dioxide $\left(\mathrm{CO}_{2}\right)$ fluxes and concentrations in terrestrial and aquatic environments using mini loggers, Biogeosciences, 12, 3849-3859, https://doi.org/10.5194/bg-12-3849-2015, 2015.

Chanton, J. P. and Whiting, G. J.: Trace gas exchange in freshwater and coastal marine environments: ebullition and transport by plants, in: Biogenic Trace Gases: Measuring Emissions from Soil and Water, edited by: Matson, P. A. and Harriss, R. C., WileyBlackwell, Oxford, 98-125, 1995.

Cole, J. J., Bade, D. L., Bastviken, D., Pace, M. L., and Bogert, M. V. D.: Multiple approaches to estimating air-water gas exchange in small lakes, Limnol. Oceanogr. Method., 8, 285-293, https://doi.org/10.4319/lom.2010.8.285, 2010. 
Deemer, B. R., Harrison, J. A., Li, S., Beaulieu, J. J., DelSontro, T., Barros, N., Bezerra-Neto, J. F., Powers, S. M., dos Santos, M. A., and Vonk, J. A.: Greenhouse Gas Emissions from Reservoir Water Surfaces: A New Global Synthesis, BioScience, 66, 949964, https://doi.org/10.1093/biosci/biw117, 2016.

DelSontro, T., McGinnis, D. F., Wehrli, B., and Ostrovsky, I.: Size Does Matter: Importance of Large Bubbles and Small-Scale Hot Spots for Methane Transport, Environ. Sci. Technol., 49, 12681276, https://doi.org/10.1021/es5054286, 2015.

Delwiche, K. and Hemond, H. F.: An enhanced bubble size sensor for long-term ebullition studies, Limnol. Oceanogr. Method., 15, 821-835, https://doi.org/10.1002/lom3.10201, 2017.

Downing, J. A., Prairie, Y. T., Cole, J. J., Duarte, C. M., Tranvik, L. J., Striegl, R. G., McDowell, W. H., Kortelainen, P., Caraco, N. F., Melack, J. M., and Middelburg, J. J.: The global abundance and size distribution of lakes, ponds, and impoundments, Limnol. Oceanogr., 51, 2388-2397, 2006.

Duc, N. T., Silverstein, S., Lundmark, L., Reyier, H., Crill, P., and Bastviken, D.: Automated Flux Chamber for Investigating Gas Flux at Water-Air Interfaces, Environ. Sci. Technol., 47, 968975, https://doi.org/10.1021/es303848x, 2012.

Duc, N. T., Silverstein, S., Wik, M., Crill, P., Bastviken, D., and Varner, R. K.: Methane and carbon dioxide fluxes, temperature and relative humidity at Mellersta Harrsjön lake, Stordalen Mire, Abisko, 2015, available at: https://bolin.su.se/ data/stordalen-ghg-sensors-2015-iot, last access: 1 July 2020.

Eugster, W. and Kling, G. W.: Performance of a low-cost methane sensor for ambient concentration measurements in preliminary studies, Atmos. Meas. Tech., 5, 1925-1934, https://doi.org/10.5194/amt-5-1925-2012, 2012.

Figaro TGS 2611 - for the detection of Methane: available at: http://www.figarosensor.com/products/docs/TGS\% 202611C00\%281013\%29.pdf (last access: 11 May 2020), 2013.

Gålfalk, M., Bastviken, D., Fredriksson, S., and Arneborg, L.: Determination of the piston velocity for water-air interfaces using flux chambers, acoustic Doppler velocimetry, and IR imaging of the water surface, J. Geophys. Res.-Biogeo., 118, 770-782, https://doi.org/10.1002/jgrg.20064, 2013.

Goodrich, J. P., Varner, R. K., Frolking, S., Duncan, B. N., and Crill, P. M.: High-frequency measurements of methane ebullition over a growing season at a temperate peatland site, Geophys. Res. Lett., 38, L07404, https://doi.org/10.1029/2011GL046915, 2011.

Goulden, M. L. and Crill, P. M.: Automated measurements of $\mathrm{CO}_{2}$ exchange at the moss surface of a black spruce forest, Tree Physiol., 17, 537-542, https://doi.org/10.1093/treephys/17.8-9.537, 1997.

Johnson, M. S., Billett, M. F., Dinsmore, K. J., Wallin, M., Dyson, K. E., and Jassal, R. S.: Direct and continuous measurement of dissolved carbon dioxide in freshwater aquatic systems - method and applications, Ecohydrology, 3, 68-78, https://doi.org/10.1002/eco.95, 2010.

Little, M. A. and Jones, N. S.: Generalized methods and solvers for noise removal from piecewise constant signals, I. Background theory, Proc. Math. Phys. Eng. Sci. Roy. Soc., 467, 3088-3114, https://doi.org/10.1098/rspa.2010.0671, 2011.

Lorke, A., Bodmer, P., Noss, C., Alshboul, Z., Koschorreck, M., Somlai-Haase, C., Bastviken, D., Flury, S., McGinnis, D. F., Maeck, A., Müller, D., and Premke, K.: Technical note: drifting versus anchored flux chambers for measuring greenhouse gas emissions from running waters, Biogeosciences, 12, 7013-7024, https://doi.org/10.5194/bg-12-7013-2015, 2015.

Luomala, J. and Hakala, I.: Effects of Temperature and $\mathrm{Hu}-$ midity on Radio Signal Strength in Outdoor Wireless Sensor Networks, Acsis.-Ann. Comput. Sci., 5, 1247-1255, https://doi.org/10.15439/2015f241, 2015.

Maeck, A., Hofmann, H., and Lorke, A.: Pumping methane out of aquatic sediments - ebullition forcing mechanisms in an impounded river, Biogeosciences, 11, 2925-2938, https://doi.org/10.5194/bg-11-2925-2014, 2014.

Marotta, H., Pinho, L., Gudasz, C., Bastviken, D., Tranvik, L. J., and Enrich-Prast, A.: Greenhouse gas production in low-latitude lake sediments responds strongly to warming, Nat. Clim. Change, 4, 467-470, https://doi.org/10.1038/nclimate2222, 2014.

Meng, L., Hess, P. G. M., Mahowald, N. M., Yavitt, J. B., Riley, W. J., Subin, Z. M., Lawrence, D. M., Swenson, S. C., Jauhiainen, J., and Fuka, D. R.: Sensitivity of wetland methane emissions to model assumptions: application and model testing against site observations, Biogeosciences, 9, 2793-2819, https://doi.org/10.5194/bg-9-2793-2012, 2012.

Ostrovsky, I., McGinnis, D. F., Lapidus, L., and Eckert, W.: Quantifying gas ebullition with echosounder: the role of methane transport by bubbles in a medium-sized lake, Limnol. Oceanogr. Method., 6, 105-118, 2008.

Smith, S. V.: Physical, chemical and biological characteristics of $\mathrm{CO}_{2}$ gas flux across the air-water interface, Plant Cell Environ., 8, 387-398, 1985.

Tassin, A. L. and Nikitopoulos, D. E.: Non-intrusive measurements of bubble size and velocity, Exp. Fluids, 19, 121-132, 1995.

Tranvik, L. J., Downing, J. A., Cotner, J. B., Loiselle, S. A., Striegle, R. G., Ballatore, T. J., Dillon, P., Finlay, K., Fortino, K., Knoll, L. B., Kortelainen, P. L., Kutser, T., Larsen, S., Laurion, I., Leech, D. M., McCallister, S. L., McKnight, D. M., Melack, J. M., Overholt, E., Porter, J. A., Prairie, Y., Renwick, W. H., Roland, F., Sherman, B. S., Schindler, D. W., Sobek, S., Tremblay, A., Vanni, M. J., Verschoor, A. M., von Wachenfeldt, E., and Weyhenmeyera, G. A.: Lakes and reservoirs as regulators of carbon cycling and climate, Limnol. Oceanogr., 54, 2298-2314, 2009.

Varadharajan, C., Hermosillo, R., and Hemond, H. F.: A lowcost automated trap to measure bubbling gas fluxes, Limnol Oceanogr. Method., 8, 363-375, 2010.

Verpoorter, C., Kutser, T., Seekell, D. A., and Tranvik, L. J.: A global inventory of lakes based on high-resolution satellite imagery, Geophys. Res. Lett., 41, 6396-6402, https://doi.org/10.1002/2014g1060641, 2014.

Vesala, T., Eugster, W., and Ojala, A.: Eddy covariance measurements over lakes, in: Eddy covariance, Springer, 365-376, 2012

Walter, B. P., Heimann, M., and Matthews, E.: Modeling modern methane emissions from natural wetlands, 1 . Model description and results, J. Geophys. Res.-Atmos., 106, 34189-34206, 2001.

Wik, M., Crill, P. M., Varner, R. K., and Bastviken, D.: Multiyear measurements of ebullitive methane flux from three subarctic lakes, J. Geophys. Res.-Biogeo., 118, 1307-1321, https://doi.org/10.1002/jgrg.20103, 2013.

Wik, M., Thornton, B. F., Bastviken, D., Uhlbäck, J., and Crill, P. M.: Biased sampling of methane release from northern lakes: A problem for extrapolation, Geophys. Res. Lett., 43, 1256-1262, https://doi.org/10.1002/2015GL066501, 2016a. 
Wik, M., Varner, R. K., Anthony, K., MacIntyre, S., and Bastviken, D.: Climate-sensitive northern lakes and ponds are critical components of methane release, Nat. Geosci., 9, 99-105, https://doi.org/10.1038/ngeo2578, 2016 b.
Yvon-Durocher, G., Allen, A. P., Bastviken, D., Conrad, R., Gudasz, C., St-Pierre, A., Thanh-Duc, N., and del Giorgio, P. A.: Methane fluxes show consistent temperature dependence across microbial to ecosystem scales, Nature, 507, 488-491, https://doi.org/10.1038/nature13164, 2014. 